\title{
Resistance to extinction as a function of the sequence of varied reward
}

\author{
DONALD T. WILLIAMS \\ York College of the City University of New York, Jamaica, New York 11451 \\ DARYL L. HOFFMAN \\ University of Oklahoma, Norman, Oklahoma 73069 \\ and \\ JAMES W. WEBSTER \\ Tech Serv Inc., BRS/LVE Division, Beltsville, Maryland 20705
}

\begin{abstract}
Rats were given six acquisition trials, one trial a day, in a straight alley with either an ascending or a descending series of varied reward magnitudes. In accordance with expectations from sequential theory, the subjects that were trained with an ascending series were more resistant to extinction than the subjects that were trained with a descending series.
\end{abstract}

The typical finding that an increase in reward magnitude from one trial to the next (ascending schedule) produces greater resistance to extinction $(\mathbf{R}$ to E) than does a descending schedule (e.g., Bowen, 1968; Leonard, 1969; Marx \& Edwards, 1966; Marx, Tombaugh, Cole, \& Dougherty, 1963; Wike \& Atwood, 1970) has been taken as support for Capaldi's $(1967,1970)$ sequential theory since ascending schedules consist of small to large reward transitions, to which sequential theory attributes increased R to E (Wike \& Atwood, 1970). However, as these studies used repeated within-day ascending or descending schedules of varied reward, they are equivocal in terms of a frustration explanation (i.e., Amsel, 1958, 1962, 1967). Specifically, if schedules are repeated over days, ascending schedules allow for a reward reduction between days and hence may produce (cf. Bower, 1962) and countercondition frustration just as descending schedules would. Moreover, because Capaldi has recently modified his position to include frustrative effects (e.g., Capaldi, 1972), it seems especially important to separate the two kinds of influences. The present study attempts to place sequential and frustrative variables in opposition and thereby ascertain their relative influence on $R$ to $E$. A limited acquisition one-trial/day paradigm is used so a given series of varied reward (either ascending or descending) is administered only once. Thus, while sequential theory would predict greater $\mathrm{R}$ to $\mathrm{E}$ with the ascending schedule, a frustration interpretation would seem to predict greater $\mathrm{R}$ to $\mathrm{E}$ with descending schedule.

Reprint requests should be sent to: Donald T. Williams, Psychology Department, York College of the City University of New York, 150-14 Jamaica Avenue, Jamaica, New York 11451. Dr. J. Bloom sponsors this paper and takes full editorial responsibility for its content.

\section{METHOD}

\section{Subjects}

The subjects were 60 naive male and female albino rats bred and raised at Indiana State University, approximately 90 to 150 days old, and were randomly assigned to two groups, balanced according to age and sex. ${ }^{1}$

\section{Apparatus}

A straight alley was used, constructed of $1.26 \mathrm{~cm}$ (.5-in.) plywood, with floor and lid covered with $.63 \mathrm{~cm}(.25$-in.) hardware cloth, and painted flat black. The inside dimensions were $12.65 \mathrm{~cm}$ (5 in.) $\times 12.65 \mathrm{~cm} \times 150.74 \mathrm{~cm}(58 \mathrm{in}$.). Four photocells controlling three Standard Electric timers provided start, run, and goal times (to $.01 \mathrm{sec}$ ) on distances of $30.36 \mathrm{~cm}, 60.72 \mathrm{~cm}, 30.36 \mathrm{~cm}(1,2$, and $1 \mathrm{ft}$ ), respectively. A manually operated guillotine door, $30.36 \mathrm{~cm}$ from the goalbox end of the alley, prevented subjects from retracing the alley. A blower attached to the goal end of the alley evacuated pheromones (olfactory cues).

\section{Procedure}

The rats received no pretraining in the apparatus and no exposure to Noyes pellets prior to the beginning of acquisition. They were placed in individual cages, where water was always available, and were gradually reduced to $80 \%$ of their ad-lib weight over a period of 10 days and maintained at this level throughout the experiment. Each group received six acquisition and 22 extinction trials, one per day. The ascending group received Reward Schedule A: 1, 2, 4, 8, 16, 32 45-mg Noyes pellets, while the descending group received Reward Schedule D: 32, 16, 8, 4, 2, 1 pellets. Nonrewarded goal confinement during extinction was $30 \mathrm{sec}$. The order of running the animals was randomized daily.

Start, run, and goal times were recorded for each trial and were summed to obtain a total time. A maximum time of $30 \mathrm{sec}$ was allowed for a rat to traverse any section of the alley, and, if this was exceeded, it was gently moved on to the next segment of the alley and $30 \mathrm{sec}$ was recorded. This procedure was required very infrequently.

\section{RESULTS}

One animal in the descending group died during 
the course of the experiment. All times were transformed to $\operatorname{logs}\left(\log _{10} 100 \mathrm{X}\right)$ for analysis. Since start, run, goal, and total running times yielded essentially the same results, only total times are reported. Figure 1 shows the total time for both groups in acquisition and extinction in blocks of two trials. A comparison of running times on the last trial of acquisition indicated no terminal acquisition differences between the two groups $\left(t_{58}=.69\right.$, $p>.05)$. There was no evidence of pattern responding in acquisition. (i.e., Group D did not respond progressively slower over trials).

In extinction, as can be seen in Figure 1, Group D appeared to be less $R$ to $E$ than Group A. An analysis of variance on the extinction data produced significant groups effect $\left(\mathrm{F}_{1,57}=13.88, \mathrm{p}<.001\right)$, trials effect $\left.\mathrm{F}_{21,1197}=8.73, \mathrm{p}<.001\right)$ and Groups by Trials interaction $\left(\mathrm{F}_{21,1197}=1.91, \mathrm{p}<.01\right)$. The results indicate that progressive response decrement occurred over extinction trials and that not only did Group A exhibit greater $\mathrm{R}$ to $\mathrm{E}$, but Group $\mathrm{A}$ also extinguished at a slower rate than Group D.

\section{DISCUSSION}

These results, along with those of previous investigations, are clearly in alignment with expectations from Capaldi's sequential model that ascending series of varied reward produce greater $R$ to $E$ than descending series, viz: conditioning the instrumental response to the memory of a smaller reward with a larger reward will occasion greater response persistence in extinction than if the instrumental response is associated with anticipatory frustrative stimuli in acquisition.

Moreover, certain design complications have been avoided. Aside from the problem mentioned earlier that reward reduction can occur between days, as well as on nonrewarded trials should they be embedded in the ascending varied reward schedule (e.g., Marx \& Edwards, 1966; Marx, Tombaugh, Cole, \& Dougherty, 1963), within-day ascending and descending schedules cause other difficulties also. For example, Wike and Atwood (1970) reported that subjects trained with within-day ascending schedules of varied reward exhibited greater $R$ to $E$ than those trained on within-day descending schedules. However, this differential $R$ to $E$ was within extinction days and may have been confounded with a variety of pattern responding. In the Wike and Atwood study (1970), the ascending schedule subjects exhibited increasing speeds over trials (i.e., within-days) in acquisition, and the descending schedule subjects had exhibited decreasing speeds over trials, within-days, in acquisition. Extinction responding then, appears to have mainly reflected a continuation of this pattern responding. The present experiment seems to have successfully circumvented these design difficulties and consequently the results provide clear support for Capaldi's sequential model.

Although still maintaining a primarily sequential-memory position, Capaldi has recently shifted away from a completely associative (i.e., noncontextual) model of instrumental conditioning (e.g., Capaldi, 1972) and has suggested that in addition to the stimulus complex produced by small reward having a time-independent nonaffective component ( $\mathrm{S}^{\mathrm{Sr}}$ ), if the small reward were a reduction from a previously experienced larger reward, there might also be a time-independent affective (i.e., frustrative) component $(\mathbf{S})$. Using a successive contrast effects situation he evaluated, in terms of generalization decrement, their relative influence and concluded that a greater amount of generalization decrement was attributed to $\mathbf{S}^{\mathbf{s r}}$ than to $S^{f}$. The results of the

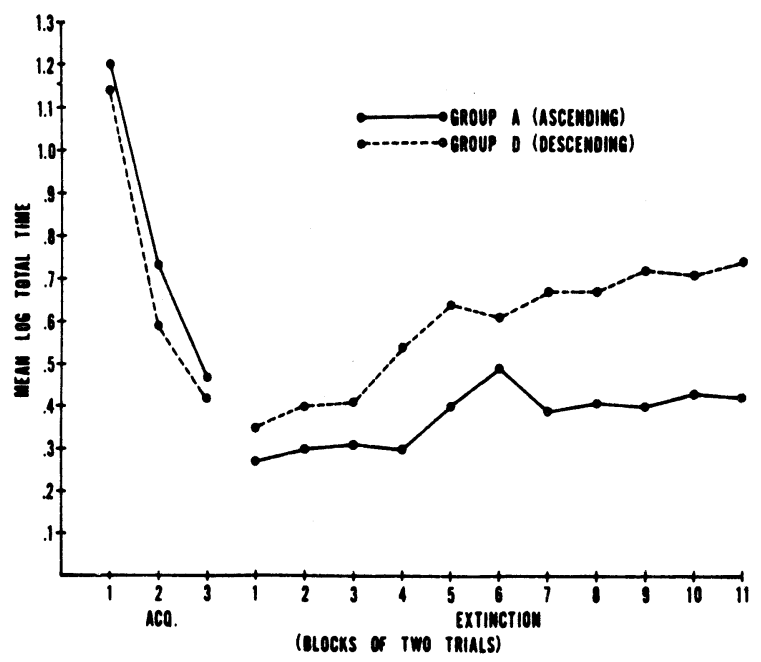

Figure 1. Mean log total running time for the ascending and descending reward groups in acquisition and extinction, in blocks of 2 days (trials).

present experiment indicate that if $S s r$ is available for the instrumental response to be conditioned to it in one group and $S f$ is available for another group, that when these two groups are compared in extinction, $S \mathbf{S r}$ is more potent in maintaining $\mathrm{R}$ to $\mathrm{E}$. That $\mathbf{S} f$ may have been present and counterconditioned in the present study is suggested, at least tentatively, by the extinction behavior of Group D. Group D maintained responding in initial extinction at the terminal acquisition level rather than evidencing very rapid response decrement in initial extinction. That is, their behavior was more similar to that of partially rewarded than continuously rewarded groups run under very comparable conditions (cf. Amsel, Hug, \& Surridge, 1968). Actually both the ascending and descending groups exhibit somewhat more response vigor in extinction than might have been expected if abbreviated partial reward. studies are used as a comparison. However, considerable response vigor in extinction following shifted reward magnitudes, and a 24-h ITI has been previously reported (Metzger, Cotton, \& Lewis, 1957).

It has already been acknowledged that sequential variables are probably influential in determining $R$ to $E$ under massed trials conditions (Amsel, 1967). The results of the present experiment indicate that sequential variables also exert considerable influence in the very spaced trial varied reward situation with limited acquisition training.

\section{REFERENCES}

Amsel, A. The role of frustrative nonreward in noncontinuous reward situations. Psychological Bulletin, 1958, 55, 102-119.

AMSEL, A. Frustrative nonreward in partial reinforcement and discrimination learning: Some history and a theoretical extension. Psychological Review, 1962, 69, 306-328.

AMSEL, A. Partial reinforcement effects on vigor and persistence: Advances in frustration theory derived from a variety of within-subjects experiments. In K. W. Spence \& J. T. Spence (Eds.). The psychology of learning and motivation (Vol. 1). New York: Academic Press, 1967.

Amsel, A.. Hug, J. J., \& Surridge, C. T. Number of food pellets, goal approaches, and the partial reinforcement effect after minimal acquisition. Journal of Experimental Psychology, 1968, 77, 530-534.

BowEN, J. Effect of ascending, descending, and irregular order of varied reward magnitude. Psychonomic Science, 1968, 12. 209-210. 


\section{WILLIAMS, HOFFMAN, AND WEBSTER}

BowER, G. H. The influence of graded reductions in reward and prior frustrating events upon the magnitude of the frustration effect. Journal of Comparative and Physiological Psychology, 1962, 55, 582-587.

CAPAldi, E. J. A sequential hypothesis of instrumental learning. In K. W. Spence \& J. T. Spence (Eds.), The Psychology of learning and motivation: Advances in research and theory (Vol. 1). New York: Academic Press, 1967.

CAPAldi, E. J. An analysis of the role of reward and reward magnitude in instrumental learning. In J. H. Renierse (Ed.), Current issues in animal learning. Lincoln, Nebraska: University of Nebraska Press, 1970.

CaPaldi, E. J. Successive negative contrast effect: Intertrial interval, type of shift, and four sources of generalization decrement. The Journal of Experimental Psychology, 1972, 96, 433-438.

LEONARD, D. Varied reward sequence and resistance to extinction in the straight alley. Psychonomic Science, 1969, 16. 129-130.

Marx, M. H., \& Edwards, D. C. Speed of nonreinforced running response following increasing and decreasing orders of sucrose concentrations. Journal of Experimental Psychology, $1966,71,160-161$.
Marx, M. H., Tombaugh, J. W., Cole, C., \& Dougherty, D. Persistence of nonreinforced responding as a function of the direction of a prior-ordered incentive shift. Journal of Experimental Psychology, 1963, 66, 542-546.

Metzger, R., Cotton, J. W., \& Lewis, D. J. Effect of reinforcement magnitude and of order of presentation of different magnitudes on runway behavior. Journal of Comparative and Physiological Psychology, 1957, 50, 184-188.

WIKE, E. L., \& ATwOod, M. E. The effects of sequences of reward magnitude, delay, and delay-box confinement upon runway performance. The Psychological Record, 1970, 20, 51-56.

\section{NOTE}

1. A large sample size was employed because the subjects received only six acquisition trials, with no prior experience with the apparatus or the Noyes pellet reward, thus, a good deal of within group variability was expected.

(Received for publication October 17, 1975.) 